\title{
Heat Stress Evaluation of Two-layer Chemical Demilitarization Ensembles with a Full Face Negative Pressure Respirator
}

\author{
Oclla Michele FLETCHER ${ }^{1}$, Ryan GUERRINA ${ }^{1}$, Candi D. ASHLEY ${ }^{2}$ \\ and Thomas E. BERNARD ${ }^{1}$ * \\ ${ }^{1}$ College of Public Health, University of South Florida, USA \\ ${ }^{2}$ School of Physical Education and Exercise Science, University of South Florida, USA \\ Received November 21, 2012 and accepted March 24, 2014 \\ Published online in J-STAGE April 24, 2014
}

\begin{abstract}
The purpose of this study was to examine the heat stress effects of three protective clothing ensembles: (1) protective apron over cloth coveralls including full face negative pressure respirator (APRON); (2) the apron over cloth coveralls with respirator plus protective pants (APRON+PANTS); and (3) protective coveralls over cloth coveralls with respirator (PROTECTIVE COVERALLS). In addition, there was a no-respirator ensemble (PROTECTIVE COVERALLSnoR), and WORK CLOTHES as a reference ensemble. Four acclimatized male participants completed a full set of five trials, and two of the participants repeated the full set. The progressive heat stress protocol was used to find the critical WBGT (WBGT crit $_{\text {) and apparent total evapora- }}$ tive resistance $\left(R_{e, T, a}\right)$ at the upper limit of thermal equilibrium. The results $\left(\mathrm{WBGT}_{\text {crit }}\left[{ }^{\circ} \mathrm{C}\right.\right.$ WBGT] and $R_{e, T, a}\left[\mathrm{kPa} \mathrm{m}^{2} \mathbf{W}^{-1}\right]$ ) were WORK CLOTHES $(35.5,0.0115)$, APRON $(31.6,0.0179)$, APRON+PANTS (27.7, 0.0244), PROTECTIVE COVERALLS (25.9, 0.0290), and PROTECTIVE COVERALLS-noR (26.2, 0.0296). There were significant differences among the ensembles. Supporting previous studies, there was little evidence to suggest that the respirator contributed to heat stress.
\end{abstract}

Key words: Heat stress, Chemical protective clothing, Respirators, Clothing adjustment factors, Evaporative resistance

\section{Introduction}

Protective clothing ensembles are worn by workers as a barrier to chemical and physical hazards. Clothing limits heat and moisture transfer between the skin and environment and hampers the loss of heat during physical effort ${ }^{1)}$. Two approaches can be taken to assess the effects of

*To whom correspondence should be addressed.

E-mail: tbernard@health.usf.edu

(C) National Institute of Occupational Safety and Health alternative clothing ensembles on heat stress. A common approach is to create conditions of uncompensable heat stress by setting the environmental conditions to one or more typical environments with a fixed metabolic rate ${ }^{2)}$. The average safe exposure time represents the ensemble performance. An alternative approach is to follow a progressive exposure protocol to determine the critical environment at the upper limit of compensable heat stress. Using data on the environmental and metabolic rate at the critical environment, the total apparent evaporative resistance $\left(\mathrm{R}_{\mathrm{e}, \mathrm{T}, \mathrm{a}}\right)^{3)}$ and the critical WBGT $\left(\mathrm{WBGT}_{\text {crit }}\right)^{4,5)}$ can be determined. $\mathrm{R}_{\mathrm{e}, \mathrm{T}, \mathrm{a}}$ and $\mathrm{WBGT}_{\text {crit }}$ are useful indices 
for the comparison of clothing ensembles with respect to evaporative cooling capacity.

The current study was undertaken to determine if there were differences in $\mathrm{WBGT}_{\text {crit }}$ and $\mathrm{R}_{\mathrm{e}, \mathrm{T}, \mathrm{a}}$ among three variations of ensembles used for chemical protection during decommissioning of chemical weapons. The three ensembles included a full face negative pressure air purifying respirator. In addition, the effect of the respirator was examined by adding a fourth protective ensemble without a respirator to the study.

\section{Subjects and Methods}

\section{Clothing}

For this study, there were five ensembles:

1. WORK CLOTHES: Cotton shirt and pants (no respirator)

2. APRON: TAP (Toxicological Agent Protective) apron $\left(\right.$ Tychem ${ }^{\circledR} F^{\circledR}$ ) (Fig. 1) over cloth coveralls with full face negative pressure air purifying respirator

3. APRON+PANTS: TAP apron and pants $\left(\right.$ Tychem $^{\circledR}$ $\mathrm{F}^{\circledR}$ ) over cloth coveralls with full face negative pressure air purifying respirator

4. PROTECTIVE COVERALLS: Protective coveralls (Tychem ${ }^{\circledR} \mathrm{F}^{\circledR}$ ) over cloth coveralls with full face negative pressure air purifying respirator

5. PROTECTIVE COVERALLS-noR: Protective coveralls $\left(\right.$ Tychem ${ }^{\circledR} \mathrm{F}^{\circledR}$ ) over cloth coveralls without respirator

The base ensemble worn during acclimatization and under all test ensembles was cotton tee shirt, gym shorts, socks and athletic shoes. Work clothes as a point of comparison were $135 \mathrm{~g} \mathrm{~m}^{-2}$ cotton shirt and $270 \mathrm{~g} \mathrm{~m}^{-2}$ cotton pants. All protective clothing options included the base ensemble, cotton coveralls, and full face negative pressure air purifying respirator. The current protective configuration was a TAP (Toxicological Agent Protection) apron, and there were two alternatives: TAP apron with chemical barrier trousers, and chemical barrier coveralls. The TAP apron (Fig. 1) was made from Tychem ${ }^{\circledR}$ F, a chemicalresistant vapor-barrier fabric. The addition of chemical barrier trousers to the TAP apron over cloth coveralls configuration or use of a chemical barrier coverall ensemble instead of the apron would offer additional protection, but at the expense of potential additional heat stress. There were no gloves or hoods worn during any of the trials.

\section{Participants}

Four acclimatized men participated in the experimen-
Table 1. Participant characteristics

\begin{tabular}{lcccc}
\hline Participant & $\begin{array}{c}\text { Age } \\
(\mathrm{yr})\end{array}$ & $\begin{array}{c}\text { Height } \\
(\mathrm{cm})\end{array}$ & $\begin{array}{c}\text { Weight } \\
(\mathrm{kg})\end{array}$ & $\begin{array}{c}\text { Body surface area } \\
\left(\mathrm{m}^{2}\right)\end{array}$ \\
\hline S1 & 21 & 1.78 & 72 & 1.89 \\
S2 $(\times 2)$ & 21 & 1.93 & 78 & 2.08 \\
S3 $(\times 2)$ & 22 & 1.80 & 106 & 2.24 \\
S4 & 22 & 1.83 & 97 & 2.19 \\
\hline
\end{tabular}

tal trials. Each participant wore all five ensembles in a counterbalanced design to avoid ordering effects, and two participants completed a second set of trials with the five ensembles following the counterbalanced design as if they were new participants. Their physical characteristics are provided in Table 1. The study protocol was approved by the University of South Florida Institutional Review Board. A written informed consent was obtained prior to enrollment in the study. Each participant was examined by a physician and approved for participation.

Participants were reminded of the need to maintain good hydration. On the day of a trial, they were asked not to drink caffeinated beverages three hours before the appointment and to refrain from vigorous exercise $24 \mathrm{~h}$ before the trial. Prior to beginning the experimental trials, participants underwent a 5-day acclimatization to dry heat that involved walking on a treadmill at a metabolic rate of approximately $170 \mathrm{~W} \mathrm{~m}^{-2}$ in a climatic chamber at $50{ }^{\circ} \mathrm{C}$ and $20 \%$ relative humidity (rh) for two hours. The base ensemble (shorts and tee shirt) was worn during acclimatization trials.

\section{Equipment}

The trials were conducted in a controlled climatic chamber. Temperature and humidity were controlled according to protocol and air speed was $0.5 \mathrm{~m} / \mathrm{sec}$. A motorized treadmill was used to control the metabolic rate and work demand through settings of speed and slope to elicit a target metabolic rate of $170 \mathrm{~W} \mathrm{~m}^{-2}$.

Heart rate (HR) was monitored using a sports-type heart rate monitor (Polar Electro, Model FT1). Rectal temperature was measured using a flexible thermistor (Measurement Specialties, Inc., Model 401AC) inserted 10-cm beyond the anal sphincter muscle. The thermistor was calibrated prior to each trial using a controlled temperature water bath. Skin temperature was measured using surface thermistors (Measurement Specialties Inc., Model 409AC) at four sites ${ }^{6}$.

Metabolic rate was estimated from assessment of oxygen consumption using a Douglas bag method with a collection 
a)

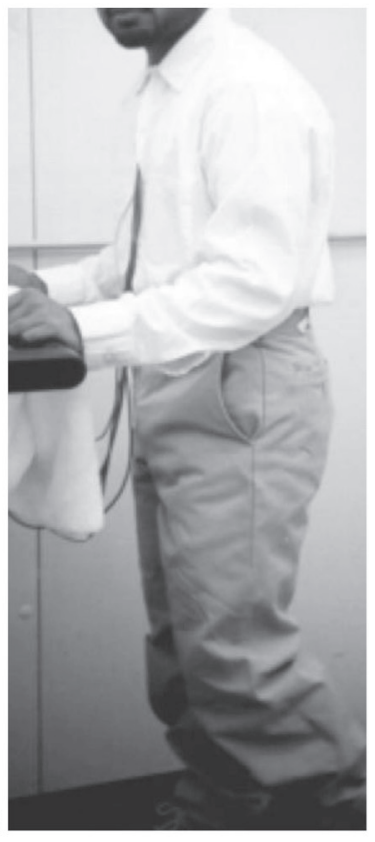

b)
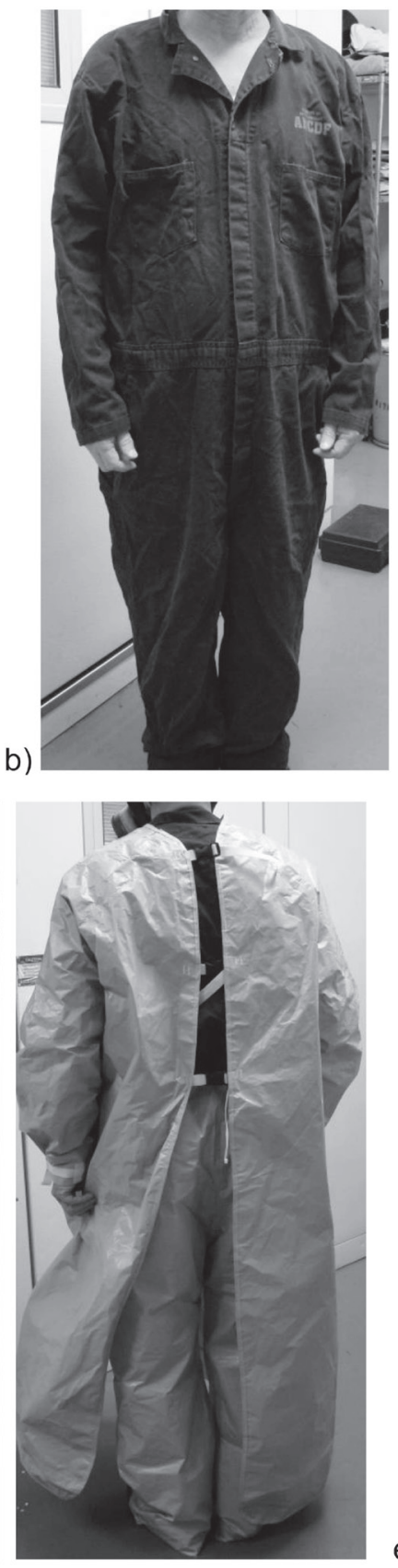

d)

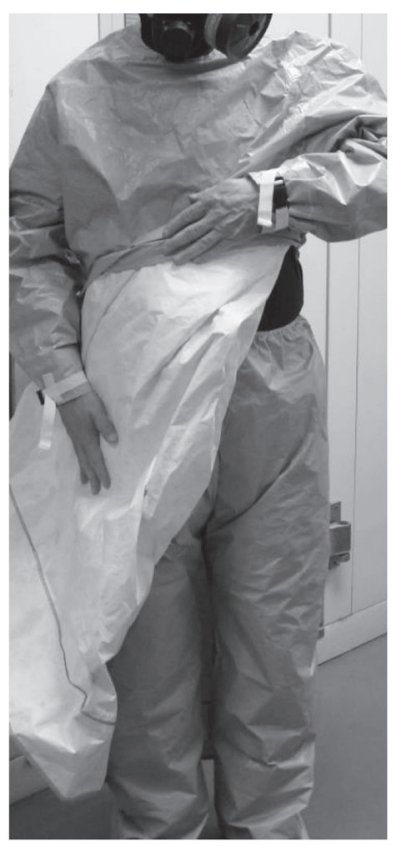

c)
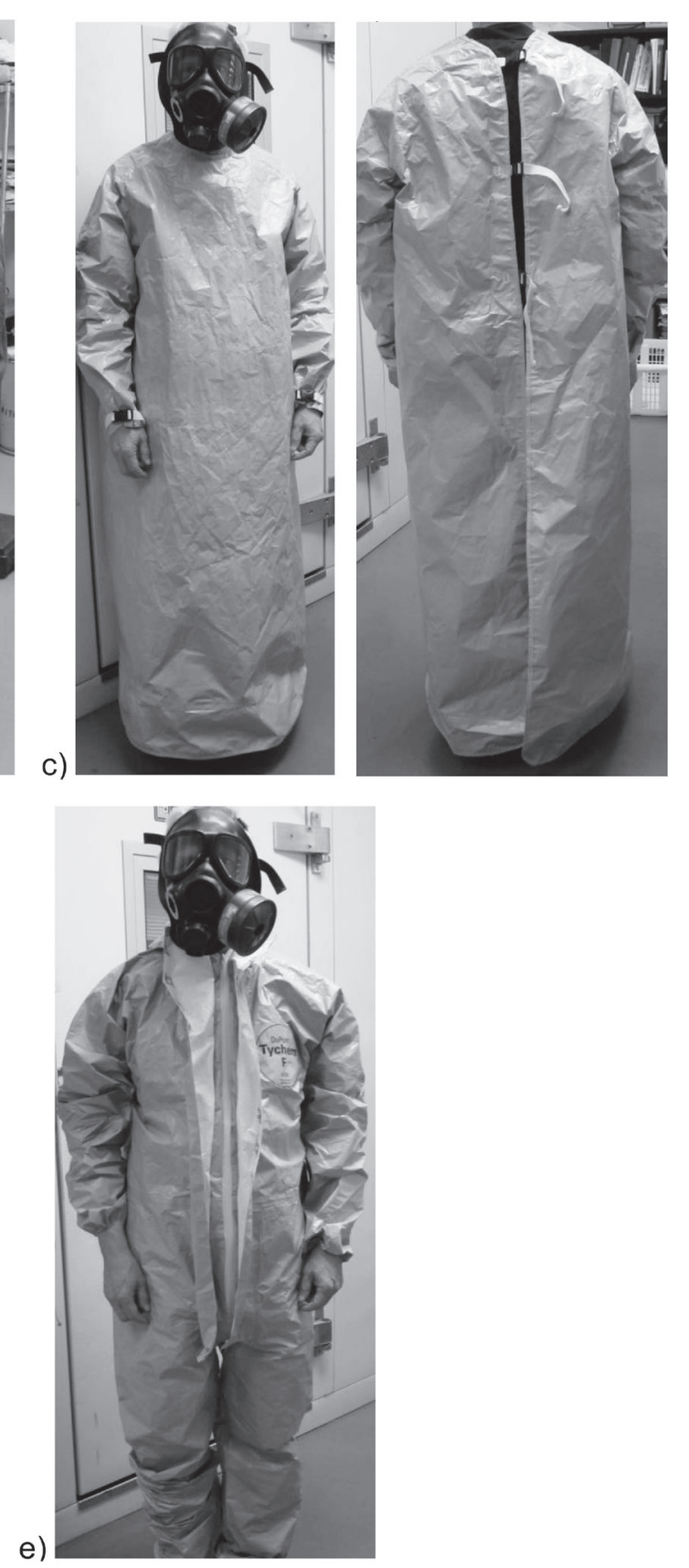

e)

Fig. 1. Ensembles: a) WORK CLOTHES, b) Coveralls worn under chemical protective clothing, c) TAP apron (front and back) and respirator, d) APRON+PANTS (front and back), and e) PROTECTIVE COVERALLS.

time of $3 \mathrm{~min}$. Immediately following collection, a small sample was removed for oxygen analysis (Vacumed Vista Mini CPX). Then the volume of expired air was measured using a dry gas meter (Rayfield Equipment).

\section{Protocols}

Each participant walked on the treadmill (Stairmaster Club Track) at a moderate rate of energy expenditure $\left(170 \mathrm{~W} \mathrm{~m}^{-2}\right)$. Initial dry bulb temperature $\left(\mathrm{T}_{\mathrm{db}}\right)$ was set according to ensemble at $35^{\circ} \mathrm{C}$ for work clothes, $28^{\circ} \mathrm{C}$ for APRON and $23{ }^{\circ} \mathrm{C}$ for the others, and relative humidity (rh) at $50 \%$. Once the participant reached thermal equilibrium (no change in $\mathrm{T}_{\mathrm{re}}$ and heart rate for at least 15 minutes), $\mathrm{T}_{\mathrm{db}}$ was increased $1{ }^{\circ} \mathrm{C}$ every 5 minutes. During trials, participants were allowed to drink water or a commercial fluid replacement beverage (Gatorade ${ }^{\circledR}$ ) at will. 
Table 2. Metabolic rate normalized to body surface area (average of three samples) and environmental conditions (dry bulb, ambient vapor pressure, and WBGT) at critical condition by ensemble (mean \pm SD based on six observations using four participants with a replicate for two participants)

\begin{tabular}{lcccc}
\hline \multicolumn{1}{c}{ Clothing Ensemble } & $\begin{array}{c}\mathrm{M}^{*} \\
\left(\mathrm{~W} \mathrm{~m}^{-2}\right)\end{array}$ & $\begin{array}{c}\mathrm{T}_{\mathrm{db} \text {, crit }} \\
\left({ }^{\circ} \mathrm{C}\right)\end{array}$ & $\begin{array}{c}\mathrm{P}_{\mathrm{a}, \text { crit }} \\
(\mathrm{kPa})\end{array}$ & $\begin{array}{c}\mathrm{WBGT}_{\text {crit }}{ }^{\circ} \\
\left({ }^{\circ} \mathrm{C}-\mathrm{WBGT}\right)\end{array}$ \\
\hline WORK CLOTHES & $167 \pm 14$ & $42.4 \pm 1.7$ & $3.69 \pm 0.62$ & $35.5 \pm 1.5$ \\
APRON & $169 \pm 21$ & $37.6 \pm 1.5$ & $3.13 \pm 0.14$ & $31.6 \pm 1.3$ \\
APRON+PANTS & $178 \pm 22$ & $33.3 \pm 1.7$ & $2.43 \pm 0.17$ & $27.7 \pm 1.3^{\mathrm{a}}$ \\
PROTECTIVE COVERALLS & $175 \pm 19$ & $31.0 \pm 1.7$ & $2.18 \pm 0.20$ & $25.9 \pm 1.4^{\mathrm{b}}$ \\
PROTECTIVE COVERALLS-noR & $172 \pm 23$ & $31.4 \pm 1.4$ & $2.24 \pm 0.14$ & $26.2 \pm 1.1^{\mathrm{a}, \mathrm{b}}$ \\
\hline
\end{tabular}

WORK CLOTHES: Cotton shirt and pants (no respirator). APRON: TAP apron over cloth coveralls with full face negative pressure air purifying respirator. APRON+PANTS: TAP apron and pants over cloth coveralls with full face negative pressure air purifying respirator. PROTECTIVE COVERALLS: Protective coveralls over cloth coveralls with full face negative pressure air purifying respirator. PROTECTIVE COVERALLS-noR: Protective coveralls over cloth coveralls without respirator. *No significant difference in metabolic rate. $\dagger$ Values of WBGTcrit with the same letter are not significantly different.

Table 3. Thermal characteristics of the clothing ensembles (total static insulation, computed resultant total insulation, apparent total evaporative resistance) as means \pm SD based on six observations using four participants with a replicate for two participants

\begin{tabular}{lccccc}
\hline \multicolumn{1}{c}{ Clothing Ensemble } & $\begin{array}{c}\mathrm{I}_{\mathrm{T}, \mathrm{stat}} * \\
\left(\mathrm{~m}^{2}{ }^{\circ} \mathrm{C} \mathrm{W}^{-1}\right)\end{array}$ & $\begin{array}{c}\mathrm{I}_{\mathrm{T}, \mathrm{r}} \\
\left(\mathrm{m}^{2}{ }^{\circ} \mathrm{C} \mathrm{W}^{-1}\right)\end{array}$ & $\begin{array}{c}\mathrm{R}_{\mathrm{e}, \mathrm{T}, \mathrm{a}}{ }^{\dagger} \\
\left(\mathrm{m}^{2} \mathrm{kPa} \mathrm{W}^{-1}\right)\end{array}$ & $\begin{array}{c}\mathrm{WBGT}_{\text {crit }}{ }^{\dagger} \\
\left({ }^{\circ} \mathrm{C}-\mathrm{WBGT}\right)\end{array}$ & $\begin{array}{c}\mathrm{CAF} \\
\left({ }^{\circ} \mathrm{C}-\mathrm{WBGT}\right)\end{array}$ \\
\hline WORK CLOTHES & 0.18 & 0.106 & $0.0112 \pm 0.0042$ & $35.5 \pm 1.5$ & 0 \\
APRON & 0.25 & 0.147 & $0.0175 \pm 0.0018$ & $31.6 \pm 1.3$ & 4 \\
APRON+PANTS & 0.27 & 0.159 & $0.024 \pm 0.0024$ & $27.7 \pm 1.3^{\mathrm{a}}$ & 8 \\
PROTECTIVE COVERALLS & 0.3 & 0.177 & $0.0287 \pm 0.0026^{\mathrm{b}}$ & $25.9 \pm 1.4^{\mathrm{b}}$ & $10 / 12^{*}$ \\
PROTECTIVE COVERALLS-noR & 0.3 & 0.177 & $0.0293 \pm 0.0034^{\mathrm{b}}$ & $26.2 \pm 1.1^{\mathrm{a}, \mathrm{b}}$ & - \\
\hline
\end{tabular}

WORK CLOTHES: Cotton shirt and pants (no respirator). APRON: TAP apron over cloth coveralls with full face negative pressure air purifying respirator. APRON+PANTS: TAP apron and pants over cloth coveralls with full face negative pressure air purifying respirator PROTECTIVE COVERALLS: Protective coveralls over cloth coveralls with full face negative pressure air purifying respirator. PROTECTIVE COVERALLS-noR: Protective coveralls over cloth coveralls without respirator. $\dagger$ Values of Re,T,a and WBGTcrit with the same letter are not significantly different. * Due to the insensitivity of vapor-barrier clothing to humidity level, $12{ }^{\circ} \mathrm{C}$-WBGT is the recommended CAF for a heat stress management program.

Core temperature, heart rate and ambient conditions (dry bulb, psychrometric wet bulb and globe temperatures, $\mathrm{T}_{\mathrm{db}}$, $\mathrm{T}_{\mathrm{pwb}}$ and $\mathrm{T}_{\mathrm{g}}$, respectively, using liquid-in-glass thermometers) were monitored continuously and recorded every $5 \mathrm{~min}$. The metabolic rate recorded for each trial was the average of three estimates of oxygen consumption taken at approximately 30,60, and $90 \mathrm{~min}$ into a trial. Metabolic rate was normalized to the DuBois estimation of body surface area ${ }^{7}$. Trials were scheduled to last $120 \mathrm{~min}$ unless one of the following criteria was met: (1) a clear rise in rectal temperature $\left(\mathrm{T}_{\mathrm{re}}\right)$ associated with a loss of thermal equilibrium (typically $0.1^{\circ} \mathrm{C}$ increase per $5 \mathrm{~min}$ for $15 \mathrm{~min}$ ), (2) $\mathrm{T}_{\mathrm{re}}$ reached $39^{\circ} \mathrm{C}$, (3) a sustained heart rate greater than $90 \%$ of the age-predicted maximum heart rate, or (4) participant wished to stop.
Inflection point, determination of critical WBGT and calculation of clothing parameters

The inflection point (critical condition) marks the transition from thermal balance to the loss of thermal balance, where core temperature continued to rise. Following the methods of previous studies ${ }^{4,5)}$, the chamber conditions $5 \mathrm{~min}$ before the noted increase in core temperature was taken as the critical condition. Moving back 5 min helped account for the thermal lag for rectal temperature. One investigator noted the critical condition and the decisions were randomly reviewed by a second investigator. Allowing that the natural wet bulb temperature is greater than $\mathrm{T}_{\mathrm{pwb}}$ by $1{ }^{\circ} \mathrm{C}$ under the chamber conditions, the critical WBGT (WBGT $\mathrm{Writ}$ ) in ${ }^{\circ} \mathrm{C}$-WBGT was computed as $0.7\left(\mathrm{~T}_{\mathrm{pwb}}+1.0\right)+0.3 \mathrm{~T}_{\mathrm{g}}^{8)}$.

The progressive heat stress protocol also provided 
Table 4. Physiological state (rectal temperature, heart rate, physiological strain index, average skin temperature, and vapor pressure at the skin) at critical conditions expressed as means \pm SD based on six observations using four participants with a replicate for two participants

\begin{tabular}{lccrcc}
\hline \multicolumn{1}{c}{ Clothing Ensemble } & $\begin{array}{c}\mathrm{T}_{\mathrm{re}} \\
\left({ }^{\circ} \mathrm{C}\right)\end{array}$ & $\begin{array}{c}\mathrm{HR} \\
(\mathrm{bpm})\end{array}$ & PSI $\dagger$ & $\begin{array}{c}\mathrm{T}_{\text {sk }} \\
\left({ }^{\circ} \mathrm{C}\right)\end{array}$ & $\begin{array}{c}\mathrm{P}_{\text {sk, crit }} \\
(\mathrm{kPa})\end{array}$ \\
\hline WORK CLOTHES & $37.6 \pm 0.3$ & $103 \pm 13$ & $2 \pm 0.8$ & $36.3 \pm 0.6$ & $6.03 \pm 0.19$ \\
APRON & $37.5 \pm 0.4$ & $107 \pm 16$ & $1.8 \pm 1.0$ & $36.4 \pm 0.2$ & $6.05 \pm 0.08$ \\
APRON+PANTS & $37.6 \pm 0.1$ & $108 \pm 13$ & $1.9 \pm 0.8$ & $36.2 \pm 0.3$ & $5.99 \pm 0.11$ \\
PROTECTIVE COVERALLS & $37.5 \pm 0.4$ & $107 \pm 12$ & $1.8 \pm 0.4$ & $36.2 \pm 0.7$ & $6.02 \pm 0.22$ \\
PROTECTIVE COVERALLS-noR & $37.7 \pm 0.2$ & $104 \pm 18$ & $1.8 \pm 0.8$ & $36.4 \pm 0.4$ & $6.08 \pm 0.14$ \\
\hline
\end{tabular}

WORK CLOTHES: Cotton shirt and pants (no respirator). APRON: TAP apron over cloth coveralls with FF-NP-APR. APRON+PANTS: TAP apron and pants over cloth coveralls with FF-NP-APR. PROTECTIVE COVERALLS: Protective coveralls over cloth coveralls with FF-NP-APR. PROTECTIVE COVERALLS-noR: Protective coveralls over cloth coveralls without respirator. $\dagger$ PSI $=5\left(\mathrm{~T}_{\mathrm{re}}-\mathrm{T}_{\mathrm{re} 0}\right) /\left(39.5-\mathrm{T}_{\mathrm{re} 0}\right)+5\left(\mathrm{HR}-\mathrm{HR}_{0}\right) /\left(180-\mathrm{HR}_{0}\right)$ where initial values were taken at time zero of trial ${ }^{14)}$

an opportunity to estimate apparent total evaporative resistance $\left(\mathrm{R}_{\mathrm{e}, \mathrm{T}, \mathrm{a}}\right)$ at the critical conditions. At the critical condition, Equation 1 applies ${ }^{3)}$.

$$
\mathrm{R}_{\mathrm{e}, \mathrm{T}, \mathrm{a}}=\left(\mathrm{P}_{\mathrm{sk}}-\mathrm{P}_{\mathrm{a}}\right) /\left(\mathrm{H}_{\mathrm{net}}+\left(\mathrm{T}_{\mathrm{db}}-\mathrm{T}_{\mathrm{sk}}\right) / \mathrm{I}_{\mathrm{T}, \mathrm{r}}\right)
$$

where

$$
\mathrm{H}_{\text {net }}=\mathrm{M}-\mathrm{W}_{\text {ext }}-\mathrm{S}+\mathrm{C}_{\text {res }}-\mathrm{E}_{\text {res }}
$$

That is, the apparent total evaporative resistance is equal to the vapor pressure difference between the skin $\left[\mathrm{P}_{\mathrm{sk}}\right]$ and the environment $\left[\mathrm{P}_{\mathrm{a}}\right]$ divided by the net heat gain due to internal sources $\left(\mathrm{H}_{\text {net }}\right.$, Equation 2$)$ plus dry heat exchange (for non-radiant environments, approximated by the difference between air $\left[\mathrm{T}_{\mathrm{db}}\right]$ and skin $\left[\mathrm{T}_{\mathrm{sk}}\right]$ temperatures divided by the resultant total insulation $\left.\left[\mathrm{I}_{\mathrm{T}, \mathrm{I}}\right]\right]^{3,9,10)}$.

To estimate resultant total insulation, static clothing insulation $\left(\mathrm{I}_{\mathrm{T}, \mathrm{stat}}\right)$ values were assigned for each ensemble. Following ISO 9920 (2007) (Equation 32), resultant clothing insulation $\left(\mathrm{I}_{\mathrm{T}, \mathrm{r}}\right)$, which adjusts for walking speed and air motion, was estimated. This is similar to the method described by Holmér et al. ${ }^{11)}$. The value of resultant clothing insulation was further reduced by $10 \%$ (multiplied by 0.9 ) to account for the reduction in insulation due to wetting ${ }^{12)}$.

$\mathrm{H}_{\text {net }}$ (Equation 2) was the metabolic rate [M] less external work $\left[\mathrm{W}_{\text {ext }}\right]$, storage rate $[\mathrm{S}]$ and respiratory heat exchange rates by convection $\left[\mathrm{C}_{\mathrm{res}}\right]$ and evaporation $\left[\mathrm{E}_{\mathrm{res}}\right]$ ). There was no slope on the treadmill so external work was taken as 0 .

Our group has taken the approach of estimating $\mathrm{I}_{\mathrm{T}, \mathrm{r}}$ and using that value to estimate $\mathrm{R}_{\mathrm{e}, \mathrm{T}, \mathrm{a}}$ (called $\mathrm{R}_{\mathrm{e}, \mathrm{T}}$ in the earlier paper), arguing that estimation of evaporative resistance is robust for estimates of clothing insulation ${ }^{3,13)}$. The CAF is the difference of the $\mathrm{WBGT}_{\text {crit }}$ for work clothes minus the $\mathrm{WBGT}_{\text {crit }}$ for the ensemble of interest.

\section{Data analysis}

The primary dependent variables were $\mathrm{R}_{\mathrm{e}, \mathrm{T}, \mathrm{a}}$ and WBGTcrit. A mixed effects ANOVA (clothing $\times$ participant [random effect]) for main effects was used. Tukey's multiple comparison test was used to determine where the differences occurred. Significance was tested at the $\alpha<0.05$ level. A similar approach was taken to assess the physiological outcomes of $\mathrm{T}_{\mathrm{re}}$, HR and Physiological Strain Index (PSI), an index of strain proposed by Moran et al. ${ }^{14)}$.

\section{Results}

In Tables 2, 3 and 4, the reported means and standard deviations assumed that each observation was independent even though there were replicates. The comparisons were based on the least square means, which were different by no more than $2 \%$ and the difference was an order of magnitude less than the standard deviation.

The metabolic rate influences the determination of WB$\mathrm{GT}_{\text {crit }}$ and $\mathrm{R}_{\mathrm{e}, \mathrm{T}, \mathrm{a}}$. Table 2 summarizes the metabolic rates and critical conditions of the environment by ensemble. For metabolic rate per unit of body surface area, there were no statistical differences among ensembles. More importantly, the range of mean metabolic rates among the ensembles was 167 to $178 \mathrm{~W} \mathrm{~m}^{-2}$, or about $6 \%$. Both the ambient air temperature and vapor pressure at the critical conditions decreased with clothing ensembles with higher evaporative resistances.

Table 3 summarizes the clothing thermal characteristics. The $\mathrm{I}_{\mathrm{T} \text {,stat }}$ values were estimated and were treated as fixed 
values for all ensembles. The $\mathrm{I}_{\mathrm{T}, \mathrm{r}}$ values were estimated following the ISO 9920 procedure ${ }^{15}$. While there were some differences among trials, the standard deviation of the resultant insulation was very small $\left(<0.001 \mathrm{~m}^{2 \circ} \mathrm{C} \mathrm{W}^{-1}\right)$ and therefore not included in the table. There were significant differences among the four ensembles (work clothes and the three variations of TAP ensembles with respirator) for $\mathrm{WBGT}_{\text {crit }}$ and $\mathrm{R}_{\mathrm{e}, \mathrm{T}, \mathrm{a}}$. For the sub-study on the respirator, there were no differences between the presence and absence of a respirator for $\mathrm{WBGT}_{\text {crit }}$ and $\mathrm{R}_{\mathrm{e}, \mathrm{T}, \mathrm{a}}$.

Table 4 summarizes the physiological heat strain by ensemble. Examining physiological state was useful to see if there may be differences by ensemble and especially for the presence versus absence of respirators. There were no significant differences among ensembles for rectal temperature, heart rate, and PSI.

\section{Discussion}

The determination of $\mathrm{WBGT}_{\text {crit }}$ is sensitive to the metabolic rate ${ }^{4)}$. The assigned metabolic rate was the average of three samples taken over the course of the trial. Because the rectal temperature was steady or slightly elevated, the thermal (Q10) effects on metabolic rate should have been minimal and thus an average should be representative. Referring to Table 2, there were no important differences in the mean metabolic rates among the ensembles with the greatest difference being about $6 \%$. Using the $11 \mathrm{~W} \mathrm{~m}^{-2}$ difference, the equivalent change in $\mathrm{WBGT}_{\text {crit }}$ would be about $0.4{ }^{\circ} \mathrm{C}-\mathrm{WBGT}$, which was small compared to the differences observed and the standard deviations reported based on the assumption that the repeated trials were independent. It was unlikely that there were systematic effects to compromise the findings for $\mathrm{WBGT}_{\text {crit }}$ or the physiological data.

\section{Critical WBGT and apparent total evaporative resistance}

For WORK CLOTHES, the WBGT $\mathrm{Writ}_{\text {cit }}$ and $\mathrm{R}_{\mathrm{e}, \mathrm{T}, \mathrm{a}}$ were $35.5^{\circ} \mathrm{C}$-WBGT and $0.0112 \mathrm{kPa} \mathrm{m}^{2} \mathrm{~W}^{-1}$. These values were virtually the same as reported in previous studies from our laboratory using the same moderate work rate and $50 \%$ relative humidity protocol ${ }^{3-5}$. The other ensembles were not tested previously. As expected, there was a progressive drop in $\mathrm{WBGT}_{\text {crit }}$ and similar increase in $\mathrm{R}_{\mathrm{e}, \mathrm{T}, \mathrm{a}}$ going from APRON to APRON+PANTS to PROTECTIVE COVERALLS, all while wearing a respirator (Table 3). This inverse relationship between $\mathrm{WBGT}_{\text {crit }}$ and $\mathrm{R}_{\mathrm{e}, \mathrm{T}, \mathrm{a}}$ was observed previously ${ }^{3)}$.

Both cloth coveralls and vapor-barrier coveralls were studied previously with reported values for $\mathrm{R}_{\mathrm{e}, \mathrm{T}, \mathrm{a}}$ of 0.013 and $0.032 \mathrm{kPa} \mathrm{m}^{2} \mathrm{~W}^{-1}$, respectively ${ }^{3)}$. The cloth coveralls in the current study were of similar weight and construction. The difference between previous vapor-barrier clothing was Tychem ${ }^{\circledR} \mathrm{QC}^{\circledR}$ versus Tychem ${ }^{\circledR} \mathrm{F}^{\circledR}$, which was stiffer. The PROTECTIVE COVERALLS had a $\mathrm{R}_{\mathrm{e}, \mathrm{T}, \mathrm{a}}$ of $0.029 \mathrm{kPa} \mathrm{m}^{2} \mathrm{~W}^{-1}$. There appeared to be little difference between a vapor-barrier ensemble alone or over cloth coveralls considering that the standard deviation of the data was about $0.003 \mathrm{kPa} \mathrm{m}^{2} \mathrm{~W}^{-1}$. The first order approximation was that the $\mathrm{R}_{\mathrm{e}, \mathrm{T}, \mathrm{a}}$ was driven by the vapor-barrier with no real contribution from the coveralls. From the current study, it is more difficult to know if the stiffness was a contributing factor. The stiffness might increase convective air movement under the PROTECTIVE COVERALLS due to the pumping factor, which would reduce the $\mathrm{R}_{\mathrm{e}, \mathrm{T}, \mathrm{a}}$. Over the whole range of ensembles, it was clear that there was an increase in evaporative resistance from APRON through APRON+PANTS to the PROTECTIVE COVERALLS. This was likely due to the progressive decrease in the degree of convective air movement under the top layer of clothing ${ }^{16-19)}$.

\section{Clothing adjustment factors}

WORK CLOTHES are the standard of comparison for Clothing Adjustment Factor (CAF). A CAF is the difference in $\mathrm{WBGT}_{\text {crit }}$ of WORK CLOTHES minus WBGT crit $_{\text {ch }}$ the ensemble of interest. Changes in CAF can help in understanding the trade-off between heat stress and chemical protection. Table 3 reports the CAFs for the ensembles. For PROTECTIVE COVERALLS, CAF was $10^{\circ} \mathrm{C}$ WBGT. When compared to the $8^{\circ} \mathrm{C}$-WBGT for a single layer vapor-barrier ensemble reported previously ${ }^{5)}$ using the same $50 \%$ rh protocol, there was an increase of about $2{ }^{\circ} \mathrm{C}$-WBGT. The difference could be due to the double layer (PROTECTIVE COVERALLS) versus the previously reported single layer vapor-barrier ensemble. The CAFs in the present study follow the $R_{e, T, a} s$ in a linear fashion as found previously ${ }^{3)}$.

The APRON ensemble already represents a significant increase in heat stress potential with a CAF of $4{ }^{\circ} \mathrm{C}$ WBGT. The further increase of $4{ }^{\circ} \mathrm{C}$-WBGT for adding pants is also very important. But the APRON+PANTS is still better from a heat stress management perspective than moving to a PROTECTIVE COVERALLS, which is a change of $6{ }^{\circ} \mathrm{C}-\mathrm{WBGT}$ from the TAP APRON. Conversely, there is some advantage to moving from PROTECTIVE COVERALLS to APRON+PANTS. Because vapor-barrier ensembles are particularly insensitive to humidity, adding 
$2{ }^{\circ} \mathrm{C}$-WBGT to the observed CAF for PROTECTIVE COVERALLS in this study would be prudent (following the logic presented elsewhere by Bernard et al. ${ }^{5)}$ ). Thus the recommended $\mathrm{CAF}$ for heat stress management purposes is $12{ }^{\circ} \mathrm{C}$-WBGT.

\section{Respirator}

User perception of a respirator is driven by comfort $^{20-24)}$. Related to comfort is respiratory effort. Negative pressure, air purifying respirators affect pulmonary ventilation by increasing inspiratory resistance and dead space ventilation thus impeding gas exchange ${ }^{25,26)}$. Johnson et $a .^{27)}$ also showed that time to volitional fatigue and respirator discomfort were related to respirator dead space volumes.

A second issue is whether there is a fundamental increase in the level of heat stress. Based on the relatively small surface area of the face compared to the whole body (about $5 \%$ ), the reduction in evaporative cooling may be a relatively small effect. This appeared to be borne out by the current study. No statistically significant differences in $\mathrm{WBGT}_{\text {crit }}$ and $\mathrm{R}_{\mathrm{e}, \mathrm{T}, \mathrm{a}}$ were observed for the presence or absence of a respirator while wearing the PROTECTIVE COVERALLS suggesting no added heat stress. The WB$\mathrm{GT}_{\text {crit }}$ would suggest a slight increase in the heat stress and the apparent total evaporative resistance would suggest a slight drop in heat stress due to the respirator. Overall, this result implies that the type of protective clothing ensemble worn will play a much bigger role in workplace heat stress risk than wearing a respirator. The effect of the respirator was examined under one clothing condition, which was the one most restrictive for evaporative cooling. Thus there was no way to know if there is an interaction between clothing and respirator. The effect of the respirator should have been greatest under this condition because a substantial surface area for evaporative cooling would be the head and hands and the respirator would have affected the head the most. With no difference in the highest evaporative resistance configuration, it is unlikely that it would have a measureable effect in lower evaporative resistance ensembles.

Many investigators found no increase in physiological burden. Looking to the physiological state at the critical conditions reported in Table 4, no significant differences were found among any of the ensembles. That is, there were no differences in rectal temperature, heart rate, skin temperature and PSI, which is a composite index for rectal temperature and heart rate. A past study of physiological state at the critical conditions without respirators also found no differences ${ }^{28)}$. So some of the findings may be due to the nature of the critical conditions. Looking to the pair of conditions designed to test for the effects of a respirator, there was no difference due to respirator. This was consistent with the findings of others using fixed environment protocols. Caretti ${ }^{29,30)}$ Scanlan $^{23)}$ and Roberge et al. ${ }^{24)}$ compared the effects of a full face, negative pressure air-purifying respirator to no respirator and found no significant differences in rectal temperature. James et al. ${ }^{31)}$ investigated the effects of respirators (no respirator and full mask negative pressure respirators) on oral temperature during low and high work demands at low and high environmental conditions. Oral temperature increased under the high work and heat conditions for both respirator treatments, suggesting that the increase in body temperature was due to the combination of higher metabolic rate and hotter environment. Notable, however, was a greater increase for the full face respirator over the other two conditions. In addition to core temperature, heart rate responses are indicative of heat strain. Most studies show no significant heart rate effects of wearing an air purifying respirators ${ }^{26)}$. Jones $^{32}$ ) and Laird et al. ${ }^{33)}$ reported that heart rate increased with work demands during the use of half face negative pressure respirators, although increases in HR due to the respirator were small when compared with overall effects of activity. Bardsley et al. ${ }^{34)}$ also showed no effect on HR due to respirator wear during moderate exercise.

In summary, there is little evidence that respirators add to the heat stress burden although they clearly cause discomfort to the user for other reasons. The current study used a heat stress approach (progressive heat stress protocol) while others looked for physiological (heat strain) effects.

A major limitation of this study was the use of four participants with replicate observations on two of them, and the use of only one clothing ensemble. But in light of the other negative findings for negative pressure air purifying respirators contributing to heat stress and strain, the current study further supported the case that negative pressure air purifying respirators do not contribute to heat stress or strain in an important way. While respirators do affect performance and comfort, they do not need to be considered in a heat stress evaluation.

\section{Study limitations}

The most obvious limitation of this study was the small sample size (four participants with two participants completing replicate trials). This presents two problems. When there was no statistically significant difference, this 
could be due to an insufficient number of observations (low power) or really no difference. This low power limit was most applicable to the respirator findings. The conclusion that respirators do not add to the heat stress burden was also supported by most of the other literature mentioned in the Discussion and thus viewed in that larger context.

Also, this study did not provide any insight into the possibility that there is an interaction between respirators and ensembles. That is, there may be an effect when the evaporative resistance of the ensembles is lower. That possibility must be investigated further before any conclusions can be drawn.

The second limitation of small sample size is the generalizability of the results to a larger population. The physical and/or physiological characteristics of the participants may not be representative. Because the apparent total evaporative resistance of WORK CLOTHES was very similar to past studies with much larger sample sizes, there is some reason to believe that the other results are generalizable.

As reported previously ${ }^{3)}$, the determination of apparent total evaporative resistance was based on many parameters that were subject to measurement error. First, the method depends on the precision of knowing the environmental conditions, which was good, and the estimation of mean skin temperature, which has a significant influence on the estimation of water vapor pressure on the skin. The internal heat generation $\left(\mathrm{H}_{\text {net }}\right)$ was dominated by the estimation of metabolic rate by oxygen consumption with some error in the estimation of respiratory heat exchange and the presumption of no external work when the treadmill was set a zero slope. Some additional error was added by estimating the resultant insulation from empirically derived relationships provided in ISO 9920. Further, pathways for heat exchange involving mass transfer were lumped into evaporative cooling.

\section{Conclusions}

There were significant differences among the clothing ensembles. As expected, the level of heat stress increased for all the protective clothing ensembles compared to WORK CLOTHES. Among the protective clothing ensembles, there was an increase going from the APRON to APRON+PANTS to PROTECTIVE COVERALLS.

Supporting previous studies, there was little evidence to suggest that the respirator contributed to heat stress. Other studies reported no change in core temperature or heart rate for a fixed metabolic rate and environment while this study looked at the effect based on heat balance.

\section{Acknowledgements}

We would like to thank the test participants and the laboratory staff for their efforts during the study. The study was supported by URS through the US Department of the Army with some support from $\mathrm{CDC} / \mathrm{NIOSH}$ training grant T42-OH008438. The authors do not represent the opinions of the US DoD or CDC.

\section{References}

1) Havenith G (1999) Heat balance when wearing protective clothing. Ann Occup Hyg 43, 289-96. [Medline] [CrossRef]

2) O'Brien C, Blanchard LA, Cadarette BS, Endrusick TL, Xu X, Berglund LG, Sawka MN, Hoyt RW (2011) Methods of evaluating protective clothing relative to heat and cold stress: thermal manikin, biomedical modeling, and human testing. J Occup Environ Hyg 8, 588-99. [Medline] [CrossRef]

3) Caravello V, McCullough EA, Ashley CD, Bernard TE (2008) Apparent evaporative resistance at critical conditions for five clothing ensembles. Eur J Appl Physiol 104, 361-7. [Medline] [CrossRef]

4) Bernard TE, Caravello V, Schwartz SW, Ashley CD (2008) WBGT clothing adjustment factors for four clothing ensembles and the effects of metabolic demands. J Occup Environ Hyg 5, 1-5, quiz d21-3. [Medline] [CrossRef]

5) Bernard TE, Luecke CL, Schwartz SW, Kirkland KS, Ashley CD (2005) WBGT clothing adjustments for four clothing ensembles under three relative humidity levels. J Occup Environ Hyg 2, 251-6. [Medline] [CrossRef]

6) Ramanathan NL (1964) A new weighting system for mean surface temperature of the human body. J Appl Physiol 19, 531-3. [Medline]

7) Du Bois D, Du Bois EF (1916) A formula to estimate the approximate surface area if height and weight be known. Arch Intern Med 17, 863-71. [CrossRef]

8) O'Connor DJ, Bernard TE (1999) Continuing the search for WBGT clothing adjustment factors. Appl Occup Environ Hyg 14, 119-25. [Medline] [CrossRef]

9) Belding HS, Kamon E (1973) Evaporative coefficients for prediction of safe limits in prolonged exposures to work under hot conditions. Fed Proc 32, 1598-601. [Medline]

10) Kenney WL, Mikita DJ, Havenith G, Puhl SM, Crosby P (1993) Simultaneous derivation of clothing-specific heat exchange coefficients. Med Sci Sports Exerc 25, 283-9. [Medline] [CrossRef]

11) Holmér I, Nilsson H, Havenith G, Parsons K (1999) Clothing convective heat exchange-proposal for improved prediction in standards and models. Ann Occup Hyg 43, 329-37. [Medline] 
12) Bröde P, Havenith G, Wang $X$, Candas V, den Hartog EA, Griefahn B, Holmér I, Kuklane K, Meinander H, Nocker W, Richards M (2008) Non-evaporative effects of a wet mid layer on heat transfer through protective clothing. Eur J Appl Physiol 104, 341-9. [Medline] [CrossRef]

13) Barker DW, Kini S, Bernard TE (1999) Thermal characteristics of clothing ensembles for use in heat stress analysis. Am Ind Hyg Assoc J 60, 32-7. [Medline] [CrossRef]

14) Moran DS, Shitzer A, Pandolf KB (1998) A physiological strain index to evaluate heat stress. Am J Physiol 275, R129-34. [Medline]

15) ISO (2007) ISO 9920: Ergonomics of the thermal environment: Estimation of the thermal insulation and evaporative resistance of a clothing ensemble, International Organization for Standarization: Geneva.

16) Bernard T, Ashley C, Trentacosta J, Kapur V, Tew S (2010) Critical heat stress evaluation of clothing ensembles with different levels of porosity. Ergonomics 53, 1048-58. [Medline] [CrossRef]

17) Havenith G, den Hartog E, Martini S (2011) Heat stress in chemical protective clothing: porosity and vapour resistance. Ergonomics 54, 497-507. [Medline] [CrossRef]

18) Gonzalez NW, Bernard TE, Carroll NL, Bryner MA, Zeigler JP (2006) Maximum sustainable work rate for five protective clothing ensembles with respect to moisture vapor transmission rate and air permeability. J Occup Environ Hyg 3, 80-6. [Medline] [CrossRef]

19) Havenith G, Richards MG, Wang X, Bröde P, Candas V, den Hartog E, Holmér I, Kuklane K, Meinander H, Nocker W (2008) Apparent latent heat of evaporation from clothing: attenuation and "heat pipe" effects. J Appl Physiol 1985 104, 142-9. [Medline] [CrossRef]

20) DuBois AB, Harb ZF, Fox SH (1990) Thermal discomfort of respiratory protective devices. Am Ind Hyg Assoc J 51, 550-4. [Medline] [CrossRef]

21) Fox SH, DuBois AB (1993) The effect of evaporative cooling of respiratory protective devices on skin temperature, thermal sensation, and comfort. Am Ind Hyg Assoc J 54, 705-10. [Medline] [CrossRef]

22) Gwosdow AR, Nielsen R, Berglund LG, DuBois AB, Tremml PG (1989) Effect of thermal conditions on the acceptability of respiratory protective devices on humans at rest. Am Ind Hyg Assoc J 50, 188-95. [Medline] [CrossRef]

23) Scanlan S, Roberts W (2001) Physiological burden of the S10. DSTO-TN-0380. Defense Science and Technology
Organization, Aeronautical and Maritime Research Laboratory, Australia.

24) Roberge R, Benson S, Kim JH (2012) Thermal burden of N95 filtering facepiece respirators. Ann Occup Hyg 56, 808-14. [Medline] [CrossRef]

25) Harber P, Tamimie RJ, Bhattacharya A, Barber M (1982) Physiologic effects of respirator dead space and resistance loading. J Occup Med 24, 681-9. [Medline] [CrossRef]

26) Martyny J, Glazer CS, Newman LS (2002) Respiratory protection. N Engl J Med 347, 824-30. [Medline] [CrossRef]

27) Johnson AT, Scott WH, Lausted CG, Coyne KM, Sahota MS, Johnson MM (2000) Effect of external dead volume on performance while wearing a respirator. AIHAJ 61, 678-84. [Medline] [CrossRef]

28) Ashley CD, Luecke CL, Schwartz SS, Islam MZ, Bernard TE (2008) Heat strain at the critical WBGT and the effects of gender, clothing and metabolic rate. Int J Ind Ergon 38, 640-4. [CrossRef]

29) Caretti DM (2000) Quantifying the Heat Stress Attributable to Respirator Wear. in Proceedings of International Society for Respiratory Protection, Syndey.

30) Caretti DM (2002) Assessment of the thermal load attributable to protective masks. In: 2001 ECBC Scientific Conference on Chemical and Biological Defense Research (Report from ADA 409494) 1-8, Hunt Valley, MD: Edgewood Chemical Biological Center, Aberdeen Proving Ground.

31) James R, Dukes-Dobos F, Smith R (1984) Effects of respirators under heat/work conditions. Am Ind Hyg Assoc J 45, 399-404. [Medline] [CrossRef]

32) Jones JG (1991) The physiological cost of wearing a disposable respirator. Am Ind Hyg Assoc J 52, 219-25. [Medline] [CrossRef]

33) Laird IS, Goldsmith R, Pack RJ, Vitalis A (2002) The effect on heart rate and facial skin temperature of wearing respiratory protection at work. Ann Occup Hyg 46, 143-8. [Medline] [CrossRef]

34) Bardsley SM, Amtmann J, Spath WK (2005) The Effects of Respirator Wear on Heart Rate and Blood Pressure During Moderate Steady-State Work. In: Proceedings of the 3rd Annual Regional National Occupational Research Agenda (NORA) Salt Lake City, Utah, 1-10, The Rocky Mountain Center for Occupational and Environmental Health, University of Utah. 